\title{
Catalytic Growth of Carbon Nanotubes by Direct Liquid Injection CVD Using the Nanocluster $\left[\mathrm{H}_{\mathrm{x}} \mathrm{PMo}_{12} \mathrm{O}_{40} \subset \mathrm{H}_{4} \mathrm{Mo}_{72} \mathrm{Fe}_{30}\left(\mathrm{O}_{2} \mathrm{CMe}\right)_{15} \mathrm{O}_{254}\right.$ $\left.\left(\mathrm{H}_{2} \mathrm{O}\right)_{98-\mathrm{y}}(\mathrm{EtOH})_{\mathrm{y}}\right]$
}

\author{
Gibran L. Esquenazi ${ }^{1}$, Bruce Brinson ${ }^{1,2}$ and Andrew R. Barron 1,2,3,* (DD \\ 1 Department of Chemistry, Rice University, Houston, TX 77005, USA; esquenazi@rice.edu (G.L.E.); \\ brinson@rice.edu (B.B.) \\ 2 Department of Materials Science and Nanoengineering, Rice University, Houston, TX 77005, USA \\ 3 Energy Safety Research Institute, Swansea University Bay Campus, Swansea SA1 8EN, UK \\ * Correspondence: arb@rice.edu or a.r.barron@swansea.ac.uk; Tel.: +1-713-348-5610
}

Received: 8 January 2018; Accepted: 26 February 2018; Published: 2 March 2018

\begin{abstract}
The growth of carbon nanotubes (CNTs) by direct liquid injection chemical vapor deposition (DLICVD) has been studied using the polyoxometalate cluster $\left[\mathrm{H}_{\mathrm{x}} \mathrm{PMo}_{12} \mathrm{O}_{40} \mathrm{C}\right.$ $\left.\mathrm{H}_{4} \mathrm{Mo}_{72} \mathrm{Fe}_{30}\left(\mathrm{O}_{2} \mathrm{CMe}\right)_{15} \mathrm{O}_{254}\left(\mathrm{H}_{2} \mathrm{O}\right)_{98-\mathrm{y}}(\mathrm{EtOH})_{\mathrm{y}}\right](\mathrm{FeMoC})$ as the catalyst with either ethanol or toluene as the carbon source. In order to screen different growth conditions a single large batch of FeMoC is required in order to eliminate variation in the catalyst precursor. The preparation of $6 \mathrm{~g}$ of FeMoC is possible by scaling $(10 \times)$ literature reagent ratios. DLICVD studies of the FeMoC derived carbon product were evaluated by Raman spectroscopy and scanning electron microscopy (SEM) to determine the quality (G:D ratio) and purity of CNT content. With the use of ethanol as the carbon source, increasing the temperature in the injection zone (aspiration temperature) above $250{ }^{\circ} \mathrm{C}$ increases the yield, and results in a slight increase in the G:D ratio. The maximum yield is obtained with a growth temperature of $900{ }^{\circ} \mathrm{C}$, while the G:D ratio is the highest at higher temperatures. Faster solution injection rates increase yield, but with a significant decrease in G:D, in fact no CNTs are observed in the product for the highest injection rate $(10 \mathrm{~mL} / \mathrm{h})$. An optimum catalyst concentration of $1.25 \mathrm{wt} . \%$ is found, which influences both the catalyst:C and catalyst:H ratios within the system. Growth at $800{ }^{\circ} \mathrm{C}$ is far more efficient for toluene as a carbon source than ethanol. The resulting "process map" allows for large quantities of CNTs to be prepared by DLICVD.
\end{abstract}

Keywords: carbon nanotube; iron; molybdenum; nanocluster; CVD; direct liquid injection

\section{Introduction}

Although carbon nanotubes (CNTs) are of interest for numerous applications, such as high-performance composites, electronics, and energy storage devices [1-6], and the current production lacks structural control, resulting in a range of chiralities and diameters. To realize their potential controlled growth of CNTs is desired. Towards this goal, engineered catalysts appear to be the ideal route. The catalyst plays a critical role in the complicated process of nucleation and growth of CNTs. Traditional catalysts for catalytic chemical vapor deposition (CCVD) growth of CNTs suffer from a lack of control in size and composition of the catalyst $[7,8]$. This is important, given the dramatic influence both size and composition have on the resulting CNTs, possibly explaining the undesirably broad distribution in diameter and chiralities observed [9-11].

The polyoxometalate cluster $\left[\mathrm{H}_{\mathrm{x}} \mathrm{PMo}_{12} \mathrm{O}_{40} \subset \mathrm{H}_{4} \mathrm{Mo}_{72} \mathrm{Fe}_{30}\left(\mathrm{O}_{2} \mathrm{CMe}\right)_{15} \mathrm{O}_{254}\left(\mathrm{H}_{2} \mathrm{O}\right)_{98-\mathrm{y}}(\mathrm{EtOH})_{\mathrm{y}}\right]$ (abbreviated as FeMoC for "iron-molybdenum cluster") appears to be an ideal catalyst for CNTs 
given its uniformity and constituent makeup. FeMoC is uniform in size ( $2.5 \mathrm{~nm}$ diameter $)$ and metal composition (i.e., Mo:Fe $=84: 30$ ). Thus, circumventing the challenges in catalyst uniformity. Additionally, FeMoC belongs to the Fe-Mo system that consists of high temperature alloys, likely to maintain their structure under CCVD conditions. The Fe-Mo system has also demonstrated excellent catalytic performance; ultra-long single walled carbon nanotubes (SWCNT) growth $(>18.5 \mathrm{~cm})$, growth of ultra-high-density SWCNTs (160 SWCNTs $\left./ \mu \mathrm{m}^{2}\right)$, and SWCNT growth under variable temperatures $\left(450-1000{ }^{\circ} \mathrm{C}\right)$ [12-15].

Liu and co-workers first reported that SWCNTs could be grown using the molecular nanocluster FeMoC [16]; however, it was found to be necessary to add an external source of iron to enable growth. Anderson et al. [17] subsequently found that even with ligand exchange and purification, the nanocluster on its own resulted in essentially no observable growth. As with the report by Liu, it was found that the specific coordination of an additional $25 \mathrm{Fe}$ atoms was required in order to achieve SWCNT growth. These results appear counter to theoretical work by Ding and co-workers that suggest the minimum size of a catalyst must be 20 atoms [18]. The addition of $25 \mathrm{Fe}$ atoms to FeMoC through coordination would suggest that 139 atoms are sufficient, but 114 are not. When considering that both Mo and Fe have demonstrated effective catalytic performance both independently and as mixed heterogenous nanoparticles [19-22], FeMoC should be catalytically active, but under the growth conditions reported in prior work it is not $[16,17,23,24]$. We have recently shown that this is in part due to both incomplete catalyst activation and the sublimation of a portion of the Mo component during the slow catalyst activation process $[25,26]$. However, the growth conditions (temperature, gas composition, carbon source, and catalyst concentration) also play role in the catalytic activity [27-30]. Therefore, we are interested in investigating the CCVD conditions that are used in CNT growth with FeMoC.

Herein, we investigate the synthesis conditions that were used for the scale-up of FeMoC: $\mathrm{pH}$ environment, air sensitivity, and relative molar ratios of reactants. Subsequently, FeMoC is used in the CCVD growth of CNTs using a direct liquid injection chemical vapor deposition (DLICVD) reactor, as depicted in Figure 1. The DLICVD system was selected given the numerous advantages it provides; i.e., ease of scale-up, fast processing time, minimal maintenance, and the versatility in fine-tuning growth parameters. The DLICVD growth parameters, aspiration temperature, growth temperature, injection rate, catalyst concentration, and carbon source, are studied in the aim of elucidating their influence on FeMoC catalyst performance. In our initial studies, we focus optimizing a "process map" for CNT growth; however, given the potentially larger scale of vapor phase growth over surface growth previously reported [17] it is also important to understand the limitations of the scalability of the synthesis of FeMoC.

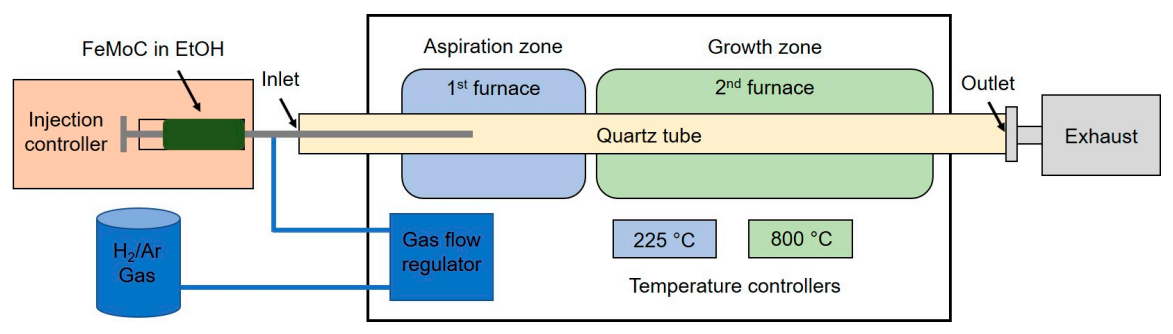

Figure 1. Schematic of the direct liquid injection chemical vapor deposition furnace.

\section{Experimental Section}

\subsection{Materials and Characterization}

FeMoC synthesis chemicals (iron(II) chloride tetrahydrate, phosphomolybdic acid hydrate, sodium molybdate, glacial acetic acid, hydrochloric acid), were purchased from Sigma-Aldrich (St. Louis, MO, USA) and were used as received. HiPco single-walled carbon nanotubes (Batch No. 188.4) 
were obtained from the Carbon Nanotube Laboratory at Rice University (Houston, TX, USA) and used as received. The 5\% hydrogen gas blend (Ar balance) was acquired from Matheson Tri-Gas (Basking Ridge, NJ, USA). Quartz tube substrates were purchased from GM Associates Inc. (product \# 6000-53, Oakland, CA, USA).

UV-visible measurements were performed on an Agilent 8453 system (Santa Clara, CA, USA) using a diluted FeMoC solution in $\mathrm{EtOH}$. Raman spectra were obtained using a Renishaw inVia Raman Microscope (Wotton-under-Edge, UK), at $514.5 \mathrm{~nm}$ wavelength, using a 50× LWD lens, data was acquired with 3 or more accumulations between $100 \mathrm{~cm}^{-1}$ and $3300 \mathrm{~cm}^{-1}$ with cosmic-ray background removal applied. FT-IR measurements were obtained using a Nicolet iS50 FTIR Infrared Microscope (Waltham, MA, USA) with an ATR objective with $2 \mathrm{~cm}^{-1}$ resolution. TEM characterization was performed on a JEOL 2100F TEM (Akishima, Tokyo, Japan) at $200 \mathrm{kV}$ equipped with a CCD camera. TEM samples were prepared by drop casting a diluted solution of FeMoC $(0.01 \mu \mathrm{M})$ in EtOH onto ultrathin lacey carbon TEM grids (400 mesh, Ted Pella, Inc., Redding, CA, USA). TGA was conducted using a TA instruments Q-600 (New Castle, DE, USA) with air as the carrier gas (Matheson Tri-Gas). Measurements were performed using $\sim 5 \mathrm{mg}$ samples that were placed in an alumina pan and heated to $900{ }^{\circ} \mathrm{C}$ with a ramp rate of $5^{\circ} \mathrm{C} / \mathrm{min}$ under a $100 \mathrm{~mL} / \mathrm{min}$ carrier gas flow. SEM was performed on a FEI Quanta 400 field emission scanning electron microscope (Hillsboro, OR, USA). SEM samples were placed on double-sided carbon tape that is fixed to aluminum SEM stubs, used as received. Images were acquired under the high vacuum setting with a typical operating voltage of $5 \mathrm{kV}$, with a working distance of $10 \mathrm{~mm}$, and spot size of 3 .

\subsection{FeMoC Synthesis}

FeMoC was synthesized and purified as previously reported [14]. In a typical synthesis, iron(II) chloride tetrahydrate $(1.00 \mathrm{~g}, 5.03 \mathrm{mmol})$ was dissolved in Millipore water $(75 \mathrm{~mL})$ followed by the addition of sodium molybdate dihydrate $(2.00 \mathrm{~g}, 8.27 \mathrm{mmol})$. To this solution, phosphomolybdic acid hydrate $(2.50 \mathrm{~g}, 1.37 \mathrm{mmol})$ and pure glacial acetic acid $(10 \mathrm{~mL}, 59 \mathrm{mmol})$ were added. $\mathrm{HCl}$ was then used to adjust the solution $\mathrm{pH}$ to 2 followed by stirring at room temperature for $45 \mathrm{~min}$. The solution was then filtered through a fine glass frit. The filtrate was then left to crystallize in air. The crystals were then vacuum filtered, washed with cold Millipore water, and dried. The resulting solid was placed in a membrane thimble and transferred to a Soxhlet extractor. After refluxing in EtOH for $12 \mathrm{~h}$, a dark green solution was collected.

\subsection{CNT Growth}

The synthesis of CNTs was carried out using a Nanotech Innovations SSP-354 two-zone liquid injection furnace [31]. A 5\% hydrogen gas blend (Ar balance) was used as the carrier gas. The flow rate for the mixed gas was held constant at $1 \mathrm{Lpm}$. The quartz furnace tube was used as the growth substrate. The DLICVD system was purged with the carrier gas for 15 min prior to heating the first zone (aspiration zone) of the furnace to either 150,225 , or $300{ }^{\circ} \mathrm{C}$ (please see 3.2. Direct Liquid Injection Chemical Vapor Deposition (DLICVD))). Then the second zone (growth zone) was set to the growth temperature $\left(700,800,900\right.$, and $\left.1000{ }^{\circ} \mathrm{C}\right)$. After reaching equilibrium, a $3 \mathrm{~mL}$ solution containing FeMoC in either EtOH or toluene was injected into the furnace via a 9" needle that was obtained from Hamilton Syringe Company (part\# 7748-12). The injection speed of 1, 5, and $10 \mathrm{~mL} / \mathrm{h}$ was controlled via a syringe pump system (KOS 106). Upon injection completion, the furnace was turned off and cooled under the $\mathrm{H}_{2}$ / Ar atmosphere. 


\section{Results and Discussion}

\subsection{Optimization of FeMoC Synthesis}

FeMoC was synthesized under a range of conditions as shown in Table 1. The synthesized products were evaluated with UV-visible spectroscopy, Raman spectroscopy, Fourier transform infrared (FT-IR) spectroscopy, and transmission electron microscopy (TEM) to verify successful synthesis of FeMoC. The higher Fe reagent concentration was investigated to more closely match the stoichiometry of the desired product. To scale FeMoC, experiments (Exp.) were also conducted using the literature (Lit.) molar ratio values, as seen in Table 1.

Table 1. Summary of $\left[\mathrm{H}_{\mathrm{x}} \mathrm{PMo}_{12} \mathrm{O}_{40} \subset \mathrm{H}_{4} \mathrm{Mo}_{72} \mathrm{Fe}_{30}\left(\mathrm{O}_{2} \mathrm{CMe}\right)_{15} \mathrm{O}_{254}\left(\mathrm{H}_{2} \mathrm{O}\right)_{98-\mathrm{y}}(\mathrm{EtOH})_{\mathrm{y}}\right](\mathrm{FeMoC})$ synthesis experiments.

\begin{tabular}{|c|c|c|c|c|c|c|c|}
\hline Exp. & $\begin{array}{c}\mathrm{FeCl}_{2} \\
(\mathrm{mmol})\end{array}$ & $\begin{array}{l}\mathrm{Na}_{2} \mathrm{MoO}_{4} \\
(\mathrm{mmol})\end{array}$ & $\begin{array}{l}\mathrm{CH}_{3} \mathrm{CO}_{2} \mathrm{H} \\
(\mathrm{mmol})\end{array}$ & $\begin{array}{c}\mathrm{H}_{3}\left[\mathrm{P}\left(\mathrm{Mo}_{3} \mathrm{O}_{10}\right)_{4}\right] \\
(\mathrm{mmol})\end{array}$ & $\mathrm{pH}^{\mathrm{a}}$ & Yield (g) ${ }^{b}$ & Notes \\
\hline 1 & 20.17 & 8.26 & 174 & 1.37 & 0.5 & 0.468 & $4 \times \mathrm{Fe}$, air \\
\hline 2 & 20.13 & 8.28 & 174 & 1.37 & 1.5 & 0.685 & $4 \times \mathrm{Fe}$ \\
\hline 3 & 201.19 & 82.661 & 1740 & 13.70 & 1.4 & 18.180 & $10 \times$ Exp. 2 \\
\hline 4 & 50.30 & 82.70 & 1740 & 13.70 & 2.0 & 6.480 & $10 \times$ Lit. \\
\hline 5 & 20.12 & 8.27 & 174 & 1.37 & 2.5 & 2.500 & $4 \times \mathrm{Fe}$ \\
\hline 6 & 20.14 & 8.29 & 174 & 1.37 & 2.0 & 2.403 & $4 \times \mathrm{Fe}$, air \\
\hline 7 & 50.55 & 82.66 & 1914 & 13.70 & 2.0 & 5.113 & $10 \times$ Lit. \\
\hline 8 & 28.82 & 47.08 & 1091 & 7.815 & 2.0 & 2.717 & $6 \times$ Lit., air \\
\hline
\end{tabular}

The UV-visible spectrum results for all growth experimental conditions are shown Figure 2. In the literature, the UV-visible spectra of FeMoC is reported to have characteristic peaks at 550, 880, and $1045 \mathrm{~nm}$, corresponding to the nucleus shell charge transfer between Keggin guest and host $(550 \mathrm{~nm})$ and the $\left[\mathrm{Mo}^{\mathrm{V}} \rightarrow \mathrm{Mo}^{\mathrm{VI}}\right]$ charge transfer in the Keggin cluster (880 and $\left.1045 \mathrm{~nm}\right)$ [17,32]. Given this information, experiments 2-4, and 7 show the characteristic features of FeMoC. The failure of experiments $1,5,6,8$ to form FeMoC are likely due to the conditions that were employed. For experiments 1,6 , and 8 the Soxhlet purification process was conducted in air. The high temperature refluxing of EtOH in the presence of air, likely results in FeMoC degradation $[33,34]$. For experiment 5 , FeMoC synthesis likely failed due to the unfavorable $\mathrm{pH}$, which controls the relative formation of the $\mathrm{Mo}^{\mathrm{VI}}$ and $\mathrm{Mo}^{\mathrm{V}}$ centers. The $\mathrm{Mo}{ }^{\mathrm{VI}}$ centers are critical in the formation of the pentagonal $\left[\mathrm{Mo}^{\mathrm{VI}}\left(\mathrm{Mo}^{\mathrm{V}}\right)_{5}\right]$ units in the polyoxometalate framework, and the $\mathrm{Mo}^{\mathrm{V}}$ centers take the role as linkers that connect the icosahedral structure. The formation of the Keplerate cage requires the coexistence of $\mathrm{Mo}^{\mathrm{VI}}$ and $\mathrm{Mo}^{\mathrm{V}}$ centers in a favorable ratio [34]. Therefore, the unfavorable $\mathrm{pH}$ environment in experiment 5 likely failed to produce FeMoC by preventing the necessary ratio of $\mathrm{Mo}^{\mathrm{VI}}$ to $\mathrm{Mo}^{\mathrm{V}}$ centers that were required to build the Keplerate cage.

For DLICVD studies, the product from experiment 4 was used. Therefore, further characterization of the products, in addition to UV-visible, was performed to confirm FeMoC synthesis. Raman spectroscopy offers a fast way to evaluate successful synthesis of FeMoC [25,32], and the Raman spectrum for experiment 4 [25] confirms the formation of FeMoC. Fourier transform infrared (FT-IR) spectroscopy results also corroborate the successful synthesis of FeMoC [25], with corresponding peaks being indicative of FeMoC $[17,32,35,36]$. Transmission electron microscopy (TEM) was also performed to verify the nanocluster size of FeMoC [25]. TEM imaging of the as synthesized product from experiment 4 reveals spherical nanoparticles with a $\sim 2.5 \mathrm{~nm}$ diameter characteristic of FeMoC from single crystal X-ray diffraction studies [32]. 
a)

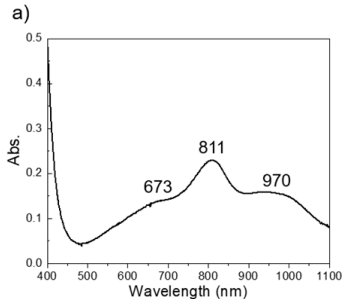

e)

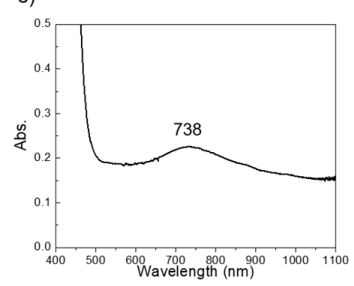

b)

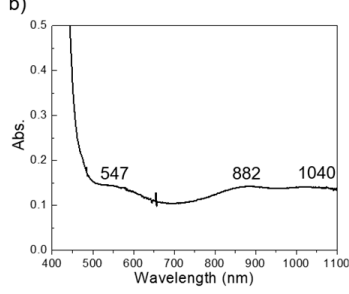

f)

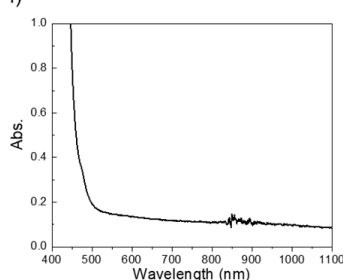

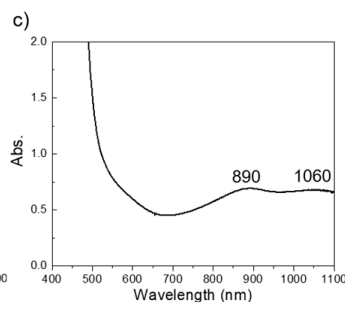

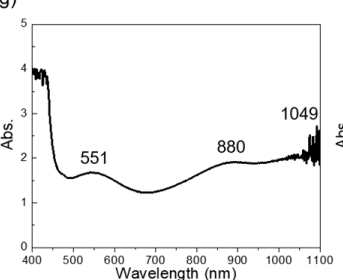

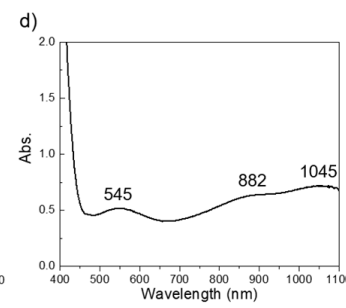

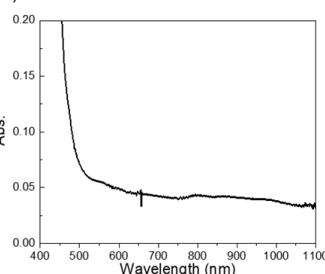

Figure 2. UV-visible spectroscopy characterization of synthesized products diluted in $\mathrm{EtOH}$ for experiments 1-8 (a-h). The corresponding peaks are labeled if applicable.

\subsection{Direct Liquid Injection Chemical Vapor Deposition (DLICVD)}

The experimental results for the catalytic growth of carbon nanomaterials using FeMoC that were carried out using various CVD conditions are shown in Table 2. The products of each experiment were characterized by Raman spectroscopy (see Supplementary Materials), revealing the quality of the CNTs as determined by the relative intensities of the $G$ and $D$ peaks. The stretching mode associated with the $G$ peak is attributed to the tangential displacement of the carbon-carbon bond stretching motions in the range of 1500 to $1600 \mathrm{~cm}^{-1}$. This $G$ peak consists of both the $\mathrm{G}-$ and $\mathrm{G}+$ bands, attributed to the $E_{2 g}$ symmetry stretching along the in-plane circumferential direction $(G-)$, and the in-plane vibrations along the tube axis $(\mathrm{G}+)$ [37]. The $\mathrm{D}$ peak is attributed to the disorder mode ( $\mathrm{A}_{1 \mathrm{~g}}$ symmetry), ranging from 1290 to $1330 \mathrm{~cm}^{-1}$ as a consequence of the lattice imperfections and crystallinity disorders [38]. Thus, the relative intensities of $\mathrm{G}$ and $\mathrm{D}$ are used to evaluate the quality of carbon materials consisting of $\mathrm{sp}^{2}$ hybridized states, such as carbon nanotubes and graphene.

Table 2. Summary of direct liquid injection chemical vapor deposition (DLICVD) experiments where temperature and concentration are abbreviated as temp. and conc. respectively.

\begin{tabular}{ccccccc}
\hline CVD Run & $\begin{array}{c}\text { Aspiration } \\
\text { Temp. }\left({ }^{\circ} \mathbf{C}\right)\end{array}$ & $\begin{array}{c}\text { Growth } \\
\text { Temp. }\left({ }^{\circ} \mathbf{C}\right)\end{array}$ & $\begin{array}{c}\text { Injection } \\
\text { Rate }(\mathbf{m L} / \mathbf{h})\end{array}$ & $\begin{array}{c}\text { Catalyst Conc. } \\
(\mathbf{w t} . \%)\end{array}$ & $\begin{array}{c}\text { Carbon } \\
\text { Source }\end{array}$ & Variable \\
\hline 1 & 150 & 800 & 1 & 1.25 & EtOH & Aspiration temp. \\
2 & 225 & 800 & 1 & 1.25 & EtOH & Aspiration temp. \\
3 & 300 & 800 & 1 & 1.25 & EtOH & Aspiration temp. \\
4 & 225 & 700 & 1 & 1.25 & EtOH & Growth temp. \\
5 & 225 & 900 & 1 & 1.25 & EtOH & Growth temp. \\
6 & 225 & 1000 & 1 & 1.25 & EtOH & Growth temp. \\
7 & 225 & 1000 & 5 & 1.25 & EtOH & Injection rate \\
8 & 225 & 1000 & 10 & 1.25 & EtOH & Injection rate \\
9 & 225 & 800 & 1 & 0.25 & EtOH & Catalyst conc. \\
10 & 225 & 800 & 1 & 5 & EtOH & Catalyst conc. \\
11 & 225 & 800 & 1 & 5 & EtOH/toluene & Carbon source \\
12 & 225 & 800 & 1 & 5 & Toluene & Carbon source \\
\hline
\end{tabular}

\subsection{Variation of Aspiration Temperature}

To elucidate the influence of the aspiration temperature (1st zone in furnace), experiments were performed using a growth temperature of $800{ }^{\circ} \mathrm{C}$, a $1 \mathrm{~mL} / \mathrm{h}$ injection rate, a $1.25 \mathrm{wt} . \%$ catalyst concentration, using EtOH as a carbon source (Table 2). The aspiration temperature will influence the carbon precursor dictating the possible mixture of complex volatile organic compounds that enter 
the reaction zone [39]. This is important because the precursor chemistry has been demonstrated to influence the CNT morphology [40]. Additionally, the aspiration temperature will also affect the temperature gradient that is entering the reaction zone. Thus, the aspiration temperature influences the inlet gas mixture composition and flows that enter the growth zone of the furnace.

Figure 3 shows the Raman characterized G:D ratio and the isolated product yield as a function of the aspiration (injection zone) temperature. The Raman results (see Supplementary Materials) reveal a small variance in G:D ratio with aspiration temperature, ranging from 1.25 to 1.56, suggesting that the aspiration temperature has little influence on the quality of the carbon materials that are produced under the conditions employed. However, the aspiration temperature is shown to have a significant influence on the product yield, which increases with increasing aspiration temperature. The increase in product yield may be attributed to the increase in carbon available for catalysis or alternatively as a consequence of the pre-decomposition of the $\mathrm{EtOH}$ (see below).
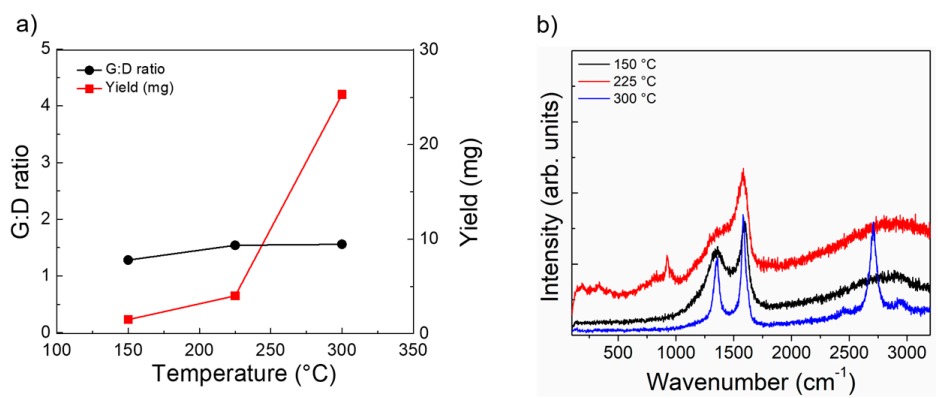

Figure 3. Plot of the Raman G:D ratio (black) and product yield (red) for DLICVD experiments with variable aspiration temperature (a) with the corresponding Raman spectra (b). Experiments were performed with a reaction temperature of $800{ }^{\circ} \mathrm{C}$, a $1 \mathrm{~mL} / \mathrm{h}$ injection rate, a $1.25 \mathrm{wt} . \%$ catalyst concentration, using EtOH as a carbon source.

Figure 4 shows growth of CNTs under all of the experimental conditions, in agreement with the Raman characterization. The SEM imaging of the product using a $150{ }^{\circ} \mathrm{C}$ aspiration temperature (Figure $4 \mathrm{a}$ ) consists of various carbon materials, including CNTs, while experiments that were conducted at $225^{\circ} \mathrm{C}$ (Figure $4 \mathrm{~b}$ ) display large CNT bundles. Finally, at an aspiration temperature of $300{ }^{\circ} \mathrm{C}$ (Figure 4c), SEM images show agglomerations of carbon materials with protruding nanostructures.
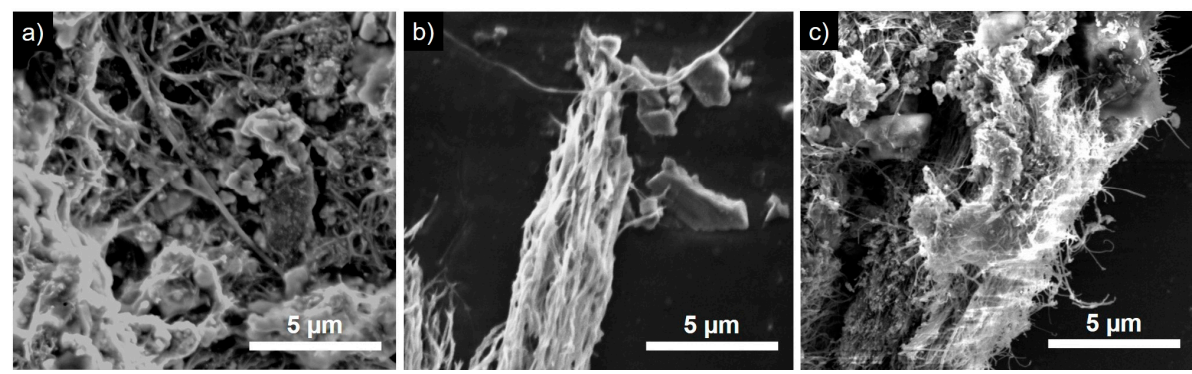

Figure 4. SEM images of DLICVD experiments conducted using a reaction temperature of $800{ }^{\circ} \mathrm{C}$, a $1 \mathrm{~mL} / \mathrm{h}$ injection rate, a $1.25 \mathrm{wt} \%$ catalyst concentration, using EtOH as a carbon source, and an aspiration temperature of (a) $150{ }^{\circ} \mathrm{C}$, (b) $225^{\circ} \mathrm{C}$, and (c) $300{ }^{\circ} \mathrm{C}$.

\subsection{Variation of Growth Temperature}

The growth temperature is expected to influence CNT product and morphology by dictating both the kinetics of hydrocarbon decomposition, and the thermodynamics of the system, namely the energy available for carbon structure arrangements. The growth temperature also plays a role in 
determining the catalyst structure and physical state (solid or liquid) that intimately influences the CNT morphology. Previous studies show that the morphology of product varies with decomposition temperature: the general trend being that an increasing temperature results in CNTs with a larger average diameter and a broader diameter distribution [41-43].

Growth temperature experiments were performed by varying the reaction temperature in the 2nd zone (growth zone, see Figure 1) of the furnace using an aspiration temperature of $225^{\circ} \mathrm{C}$, an injection rate of $1 \mathrm{~mL} / \mathrm{h}$, a $1.25 \mathrm{wt}$.\% catalyst concentration, and EtOH as a carbon source (Table 2). The experimental results for variable growth temperature are shown in Figure 5. The Raman G:D ratio shows little variance in the $700-900{ }^{\circ} \mathrm{C}$ growth temperature range, but at a growth temperature of $1000{ }^{\circ} \mathrm{C}$ the G:D ratio increases $\sim 3 \times(4.22)$ as compared to that observed for growth at $900{ }^{\circ} \mathrm{C}$ (1.37). The increase in growth temperature appears to provide a more favorable growth environment for carbon nanotubes. This transition in CNT growth at temperatures $>900{ }^{\circ} \mathrm{C}$ agrees with prior work using FeMoC $[16,17,23,24,44]$, suggesting that FeMoC has a temperature dependent activation mechanism for CNT growth [26]. Product yield for the growth temperature experiments is shown to increase when the growth temperature is increased from $700{ }^{\circ} \mathrm{C}$ to $900{ }^{\circ} \mathrm{C}$. This is followed by a decrease in product yield when increasing the growth temperature to $1000^{\circ} \mathrm{C}$. This growth temperature relationship with product yield likely arises from the temperature dependent behavior of the kinetics of hydrocarbon decomposition.
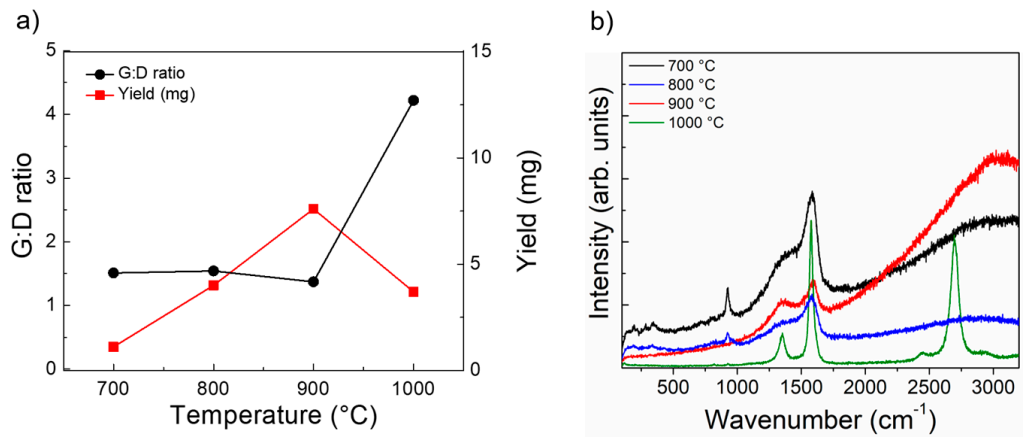

Figure 5. Plot of the Raman G:D ratio (black) and product yield (red) for DLICVD experiments with variable growth temperature (a) with the corresponding Raman spectra (b). Experiments were performed with an aspiration temperature of $225^{\circ} \mathrm{C}$, a $1 \mathrm{~mL} / \mathrm{h}$ injection rate, a $1.25 \mathrm{wt} . \%$ catalyst concentration, using EtOH as a carbon source.

The SEM images for the growth temperature experiments are shown in Figure 6. At a growth temperature of $700{ }^{\circ} \mathrm{C}$ (Figure 6a), SEM imaging reveals the presence of CNTs decorated on the surfaces of large agglomerations. At growth temperatures of $800{ }^{\circ} \mathrm{C}$ and $900{ }^{\circ} \mathrm{C}$ SEM show long CNT bundles further corroborating the Raman characterization. The synthesized product at $1000{ }^{\circ} \mathrm{C}$ appears to be dominated by CNTs in agreement with the favorable Raman spectroscopy measurements.

The TEM images at two magnifications for the growth temperature experiments are shown in Figure 7. At a $700{ }^{\circ} \mathrm{C}$ growth temperature (Figure 7a), TEM imaging reveals the presence of MWCNTs, with an average diameter of $51 \mathrm{~nm}$ and agglomerations of catalyst and carbon residue. The curly and tangled MWCNT morphology makes the reporting lengths and subsequent aspect ratios difficult. Therefore, only the average diameter is reported here. At an $800^{\circ} \mathrm{C}$ growth temperature (Figure $7 \mathrm{~b}$ ), TEM images display tangled MWCNTs with an average diameter of $27 \mathrm{~nm}$. TEM imaging at a $900{ }^{\circ} \mathrm{C}$ growth temperature reveals MWCNTs with an average diameter of $9 \mathrm{~nm}$. At a $1000{ }^{\circ} \mathrm{C}$ growth temperature, MWCNT are observed with a distinctly less curly morphology and an average diameter of $8 \mathrm{~nm}$. The TEM observations display a decreasing CNT diameter trend with an increasing growth temperature. 

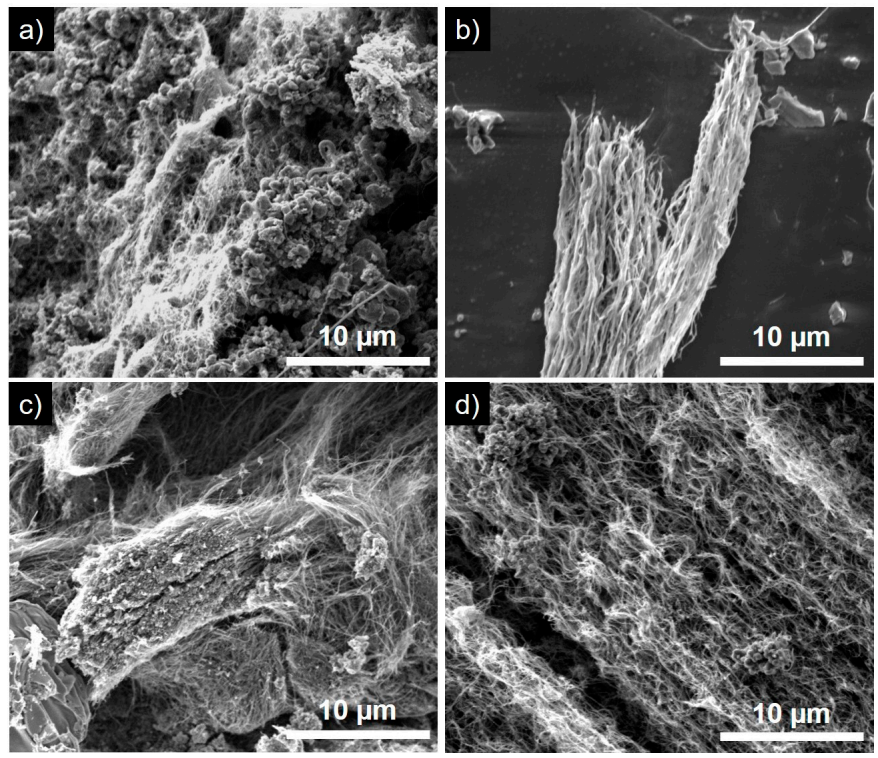

Figure 6. SEM images of DLICVD experiments conducted using an aspiration temperature of $225^{\circ} \mathrm{C}$, a $1 \mathrm{~mL} / \mathrm{h}$ injection rate, a $1.25 \mathrm{wt}$ \% catalyst concentration, using $\mathrm{EtOH}$ as a carbon source, and a reaction temperature of $(\mathbf{a}) 700{ }^{\circ} \mathrm{C}$, (b) $800{ }^{\circ} \mathrm{C}$, (c) $900{ }^{\circ} \mathrm{C}$, and (d) $1000{ }^{\circ} \mathrm{C}$.
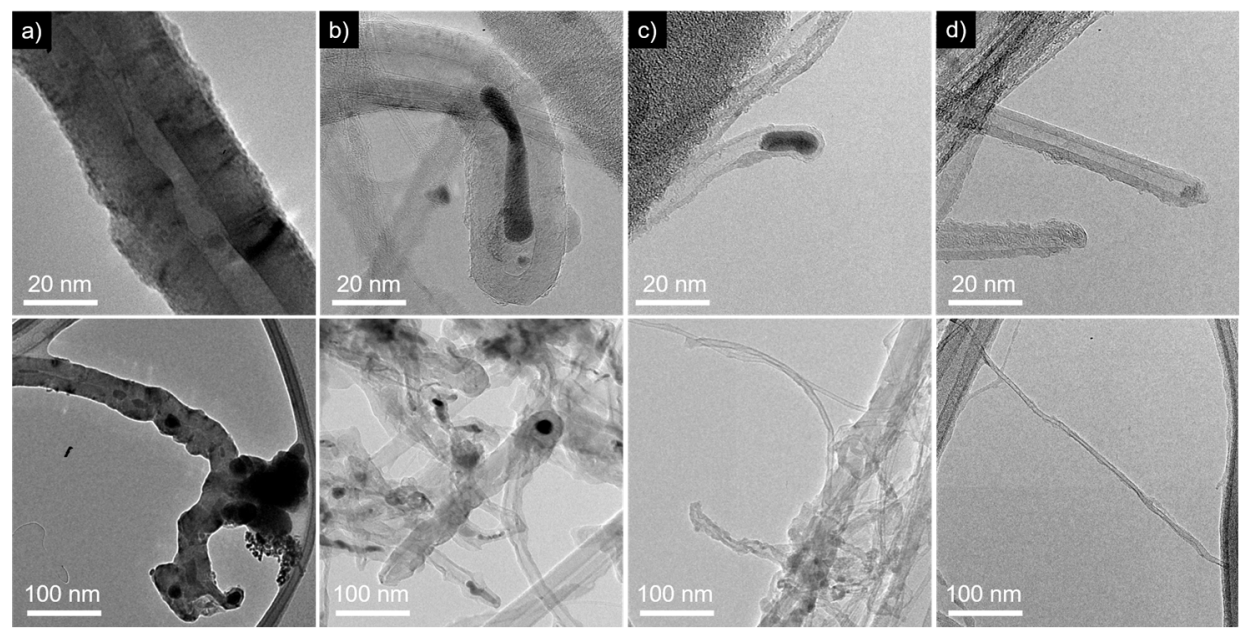

Figure 7. TEM images of DLICVD experiments at high magnification (top) and low magnification (bottom) conducted using an aspiration temperature of $225^{\circ} \mathrm{C}$, a $1 \mathrm{~mL} / \mathrm{h}$ injection rate, a $1.25 \mathrm{wt} . \%$ catalyst concentration, using $\mathrm{EtOH}$ as a carbon source, and a reaction temperature of (a) $700{ }^{\circ} \mathrm{C}$, (b) $800{ }^{\circ} \mathrm{C}$, (c) $900{ }^{\circ} \mathrm{C}$, and (d) $1000^{\circ} \mathrm{C}$.

Further characterization of the growth temperature experiments was carried out using thermogravimetric analysis (TGA), as seen in Figure 8. The TGA results show that the residual weight decreases with increasing temperature, suggesting that increased growth temperatures improve CNT product purity. The weight loss onset for 700,800 , and $900{ }^{\circ} \mathrm{C}$ growth temperature experiments begins at $\sim 300{ }^{\circ} \mathrm{C}$ accompanied by varying slopes of weight loss. The increasing rate loss slope with increasing growth temperature suggests that less carbon impurities are present in the CNT product at higher growth temperatures, which is in agreement with the TEM observations. At the highest growth temperature, $1000{ }^{\circ} \mathrm{C}$, the TGA results show a weight loss onset temperature at $\sim 500{ }^{\circ} \mathrm{C}$ with the sharpest rate loss slope and least residual weight (22.5\%), indicating the highest purity and quality CNT product, in agreement with both the TEM and Raman characterization. 


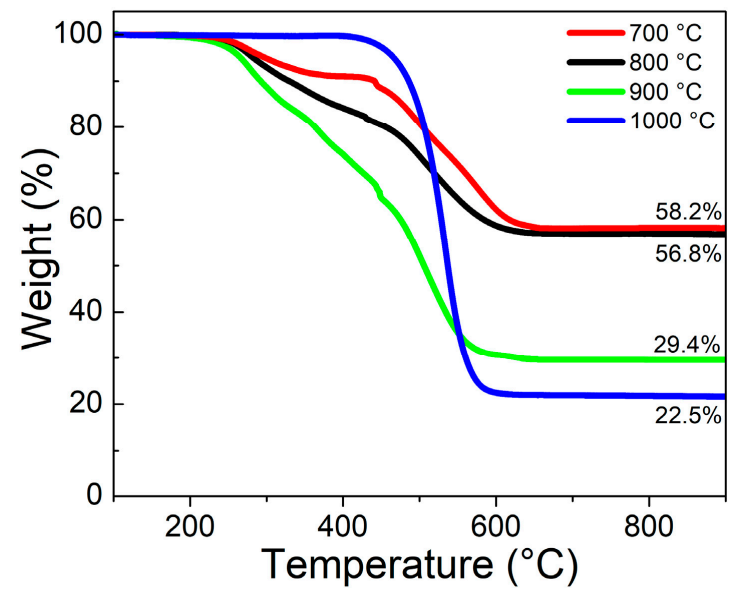

Figure 8. Thermogravimetric analysis (TGA) results of DLICVD experiments, performed at an aspiration temperature of $225^{\circ} \mathrm{C}$, a $1 \mathrm{~mL} / \mathrm{h}$ injection rate, a $1.25 \mathrm{wt} . \%$ catalyst concentration, using EtOH as a carbon source, and a reaction temperature of $700{ }^{\circ} \mathrm{C}$ (red), $800{ }^{\circ} \mathrm{C}$ (black), $900{ }^{\circ} \mathrm{C}$ (green), and $1000{ }^{\circ} \mathrm{C}$ (blue) with the corresponding residual weights labeled.

\subsection{Variation of Injection Rate}

The injection rate of the solution into the carrier gas will alter both the $\mathrm{C}: \mathrm{H}$ ratio and the catalyst:H ratio. A high catalyst:H ratio may result in incomplete reduction of the pro-catalyst. Additionally, a high C:H ratio may result in a decreased product yield via catalyst deactivation by encapsulation of catalytically active sites [45]. Prior work has shown that the $\mathrm{C}: \mathrm{H}$ ratio in the growth zone has significant effects on the growth rate of CNTs $[30,46]$. Furthermore, our research has previously shown for the DLICVD system that increased injection rates using ferrocene in toluene resulted in lower yields of CNTs [31]. This is consistent with lower growth rates that are expected for higher C:H ratios.

Injection rate experiments were performed by varying the injection rate of the FeMoC solution into the furnace using an aspiration temperature of $225^{\circ} \mathrm{C}$, a growth temperature of $1000{ }^{\circ} \mathrm{C}$, a $1.25 \mathrm{wt} . \%$ catalyst concentration, and EtOH as a carbon source (Table 2). The Raman characterization and product yield results for injection rate experiments are shown in Figure 9. The Raman G:D ratio is shown to decrease with an increasing injection rate from a G:D ratio of 4.22 to 1.36 for injection rates of 1 and $5 \mathrm{~mL} / \mathrm{h}$, respectively. Using an injection rate of $10 \mathrm{~mL} / \mathrm{h}$, the Raman G:D ratio is shown to slightly increase from 1.36 to 1.58 for injection rates of 5 and $10 \mathrm{~mL} / \mathrm{h}$, respectively. The injection rate of the solution into the carrier gas influences both the catalyst:H ratio, and the $\mathrm{C}: \mathrm{H}$ ratio. Thus, the results here suggest that reducing the $\mathrm{C}: \mathrm{H}$ and the catalyst: $\mathrm{H}$ ratios provides a more favorable environment for producing quality CNTs. From Figure 9, we observe that the product yield increases with injection rate from $3.7 \mathrm{mg}$ to $5.4 \mathrm{mg}$ for $1 \mathrm{~mL} / \mathrm{h}$ and $10 \mathrm{~mL} / \mathrm{h}$, respectively. This increased product yield is likely due to the increased quantity of both carbon source material and catalyst particles that are available in the system.

The SEM micrographs for variable injection rate experiments are shown in Figure 10. At a $1 \mathrm{~mL} / \mathrm{h}$ injection rate, SEM reveals an abundance of CNTs (Figure 10a), as corroborated by the Raman characterization. Using an injection rate of $5 \mathrm{~mL} / \mathrm{h}$ (Figure 10b), SEM micrographs show CNTs to a lesser degree in both quantity and quality. At a $10 \mathrm{~mL} / \mathrm{h}$ injection rate (Figure 11c), even fewer CNTs are observed. Thus, SEM evidence shows that the quantity and quality of CNTs decreases with an increasing injection rate in agreement with the Raman characterization. 
a)

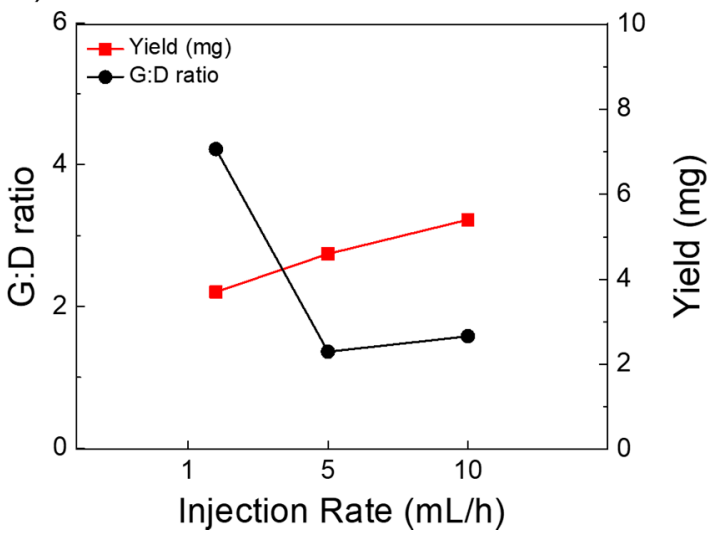

b)

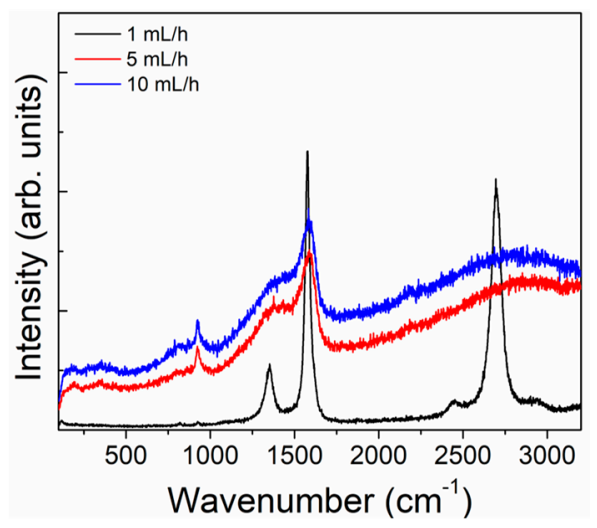

Figure 9. Plot of the Raman G:D ratio (black) and product yield (red) for DLICVD experiments with variable injection rate (a) with the corresponding Raman spectra (b). Experiments were performed with an aspiration temperature of $225^{\circ} \mathrm{C}$, a reaction temperature of $1000{ }^{\circ} \mathrm{C}$, a $1.25 \mathrm{wt} . \%$ catalyst concentration, using $\mathrm{EtOH}$ as a carbon source.
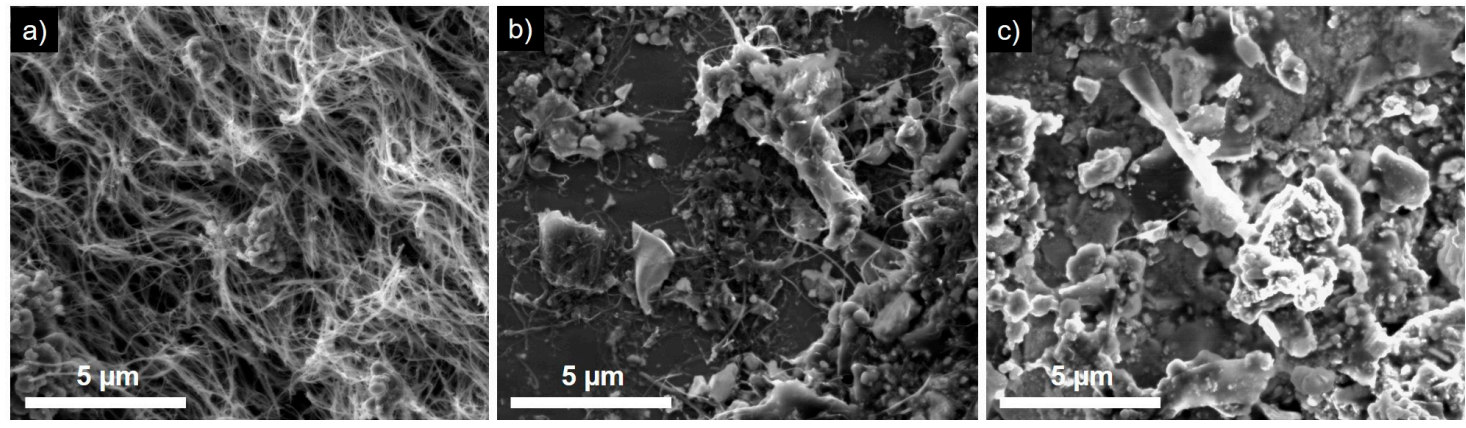

Figure 10. SEM images of DLICVD experiments conducted using an aspiration temperature of $225^{\circ} \mathrm{C}$, a reaction temperature of $1000^{\circ} \mathrm{C}$, a $1.25 \mathrm{wt} . \%$ catalyst concentration, using $\mathrm{EtOH}$ as a carbon source, and an injection rate of (a) $1 \mathrm{~mL} / \mathrm{h}(\mathbf{b}) 5 \mathrm{~mL} / \mathrm{h}$, and (c) $10 \mathrm{~mL} / \mathrm{h}$.

\subsection{Variation of Catalyst Concentration}

The catalyst concentration will determine both the catalyst: $\mathrm{C}$ and catalyst:H ratios that influence the resulting CNT morphology and product yield. If catalyst concentrations are too high, catalyst aggregation may result upon the evaporation of solvent from individual aspirated droplets, which in turn favors undesirable carbon structures, rather than the intended CNTs. However, if catalyst concentrations are too low, the CNT product yield may suffer due to limited catalyst site availability. Therefore, careful consideration of catalyst concentration is required for optimal performance.

To investigate the influence of catalyst concentration experiments were performed using an aspiration temperature of $225^{\circ} \mathrm{C}$, a growth temperature of $800{ }^{\circ} \mathrm{C}$, a $1 \mathrm{~mL} / \mathrm{h}$ injection rate, and $\mathrm{EtOH}$ as the carbon source (see Table 2) The Raman G:D ratio and product yield from catalyst concentration experiments are shown in Figure 11. At a catalyst concentration of 0.25 and $5.00 \mathrm{wt} . \%$, no synthesized product was recovered, and thus, no Raman characterization could be conducted. However, at a catalyst concentration of $1.25 \mathrm{wt} . \%, \sim 4 \mathrm{mg}$ of the synthesized product was recovered, with a corresponding Raman G:D ratio of 1.54. It would appear that further optimization would be beneficial to find the "Goldilocks" zone, i.e., an optimal region between two extremes advantageous to CNT growth [47]. 


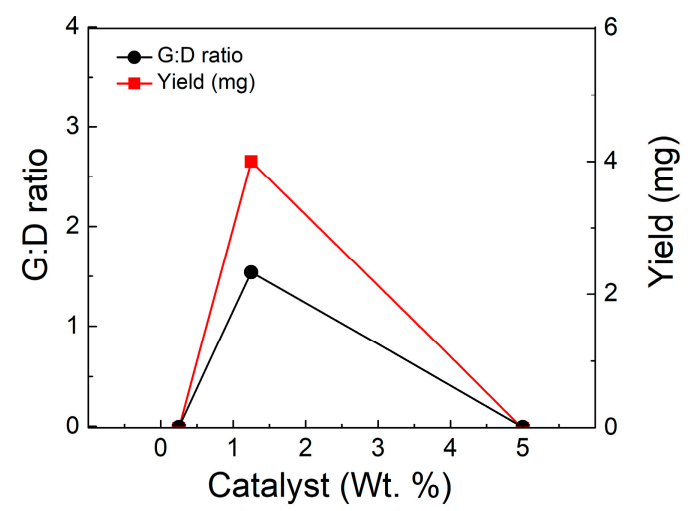

Figure 11. Plot of the Raman G:D ratio (black) and product yield (red) for DLICVD experiments with variable catalyst concentration (wt.\%). Experiments were performed with an aspiration temperature of $225^{\circ} \mathrm{C}$, a reaction temperature of $800{ }^{\circ} \mathrm{C}$, an injection rate of $1 \mathrm{~mL} / \mathrm{h}$, and EtOH as the carbon source.

\subsection{Variation in Carbon Source}

The choice of carbon source, hydrocarbons, or increasingly more common alcohols, can influence the nature of the CNT quality and product yield due to their varying decomposition products that determine CNT quality, morphology, and growth rate [48]. Furthermore, the choice of carbon source also impacts the relative $\mathrm{C}: \mathrm{H}$ and the $\mathrm{C}$ :catalyst ratios that also influence $\mathrm{CNT}$ morphology and product yield. If carbon ratios are too low, then CNT product yield may suffer; if carbon ratios are too high, the catalyst may be "deactivated" via catalyst encapsulation. Therefore, carbon source selection is vital to optimizing CNT production.

To elucidate the effects of carbon source, experiments were conducted using an aspiration temperature of $225^{\circ} \mathrm{C}$, a growth temperature of $800{ }^{\circ} \mathrm{C}$, an injection rate of $1 \mathrm{~mL} / \mathrm{h}$, a $5.00 \mathrm{wt} . \%$ catalyst concentration, using varying degrees of toluene in $\mathrm{EtOH}$ as the carbon source. The Raman G:D ratio and product yield for the carbon source experiments are shown in Figure 12. Using only $\mathrm{EtOH}$ as the carbon source resulted in no product yield under the conditions that were employed (Table 2). Using a carbon source consisting of $\mathrm{EtOH}$ and toluene (1:1 wt.\%) resulted in $52.3 \mathrm{mg}$ product yield with a corresponding Raman G:D ratio of 1.74. Further improvements were obtained when using $100 \%$ toluene as the carbon source, resulting in a product yield of $80.5 \mathrm{mg}$ and a Raman G:D ratio of 3.6. The carbon source is known to influence the nature of synthesized product due to the varying hydrocarbon decomposition species.

Toluene thermally decomposes by either fission of the C-H bond in the methyl group (Equation (1)) or by cleavage of the C-C bond connecting the methyl and phenyl groups (Equation (2)) $[49,50]$. The benzyl radical formation (Equation (1)) dominates under the CVD conditions that are employed here; therefore, the subsequent decomposition is outlined in Equations (3) and (4) [49].

$$
\begin{gathered}
\mathrm{C}_{6} \mathrm{H}_{5} \mathrm{CH}_{3} \rightarrow \mathrm{C}_{6} \mathrm{H}_{5} \mathrm{CH}_{2}+\mathrm{H} \\
\mathrm{C}_{6} \mathrm{H}_{5} \mathrm{CH}_{3} \rightarrow \mathrm{C}_{6} \mathrm{H}_{5}+\mathrm{CH}_{3} \\
\mathrm{C}_{6} \mathrm{H}_{5} \mathrm{CH}_{2} \rightarrow \mathrm{C}_{3} \mathrm{H}_{3}+\mathrm{C}_{4} \mathrm{H}_{4} \\
\mathrm{C}_{6} \mathrm{H}_{5} \mathrm{CH}_{2} \rightarrow \mathrm{C}_{5} \mathrm{H}_{5}+\mathrm{C}_{2} \mathrm{H}_{2}
\end{gathered}
$$

$\mathrm{EtOH}$ is known to decompose by either the dehydration reaction seen in Equation (5) or by cleavage of the $\mathrm{C}-\mathrm{C}$ bond connecting the methyl group and the methylene group as seen in Equation (6) [51,52]. The dehydration reaction (Equation (5)) dominates under the conditions that are employed here [52].

$$
\mathrm{CH}_{3} \mathrm{CH}_{2} \mathrm{OH} \rightarrow \mathrm{C}_{2} \mathrm{H}_{4}+\mathrm{H}_{2} \mathrm{O}
$$




$$
\mathrm{CH}_{3} \mathrm{CH}_{2} \mathrm{OH} \rightarrow \mathrm{CH}_{3}+\mathrm{CH}_{2} \mathrm{OH}
$$

The thermal decomposition of carbon sources $\mathrm{EtOH}$ and toluene result in the formation of $\mathrm{C}_{\mathrm{x}}$ $(x=2-5)$ species that are then subsequently used in the growth of carbon nanotubes. These $C_{x}$ species differ in metal/support adsorption energies that dictate (1) carbon association with the catalyst nanoparticle, (2) nanotube quality, and (3) nanotube chirality and growth rate [53]. Therefore, the CNT growth results observed here are likely a result of the complicated interplay between the thermal decomposition species and the FeMoC catalyst. In addition, CNT quality and yield are influenced by the presence of oxygen containing species, such as EtOH and $\mathrm{H}_{2} \mathrm{O}$. Oxygen containing species are known to etch carbon materials under CNT growth conditions [54-56]. This may possibly explain the decrease in quality and product yield observed with increasing EtOH content.

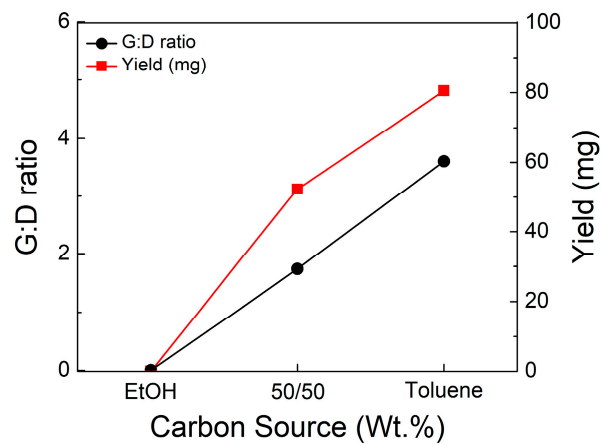

Figure 12. Plot of the Raman G:D ratio (black) and product yield (red) for DLICVD experiments with the carbon source consisting of varying degrees of toluene in EtOH. Experiments were performed with an aspiration temperature of $225^{\circ} \mathrm{C}$, a reaction temperature of $800{ }^{\circ} \mathrm{C}$, an injection rate of $1 \mathrm{~mL} / \mathrm{h}$, and a $5.00 \mathrm{wt}$ \% catalyst concentration.

\section{Conclusions}

We have evaluated the conditions used in scaling up FeMoC synthesis into the gram scale, and investigated the CCVD conditions employed in CNT growth. The synthesis conditions; $\mathrm{pH}$ environment, air sensitivity, and relative molar ratios of reactants were evaluated. The results reveal that the successful scale-up of FeMoC is sensitive to both the presence of air, and the $\mathrm{pH}$ environment. Soxhlet purification in air led to degradation. Additionally, experimental results suggest that successful FeMoC synthesis requires a favorable $\mathrm{pH}$ environment ( 0.5-2.0); likely to maintain the desirable ratios of $\mathrm{Mo}^{\mathrm{VI}}$ and $\mathrm{Mo}^{\mathrm{V}}$ centers required to form the Keplerate cage [34].

Subsequently, DLICVD was used to grow CNTs using FeMoC. The CCVD conditions: aspiration temperature, growth temperature, injection rate, catalyst concentration, and carbon source, were investigated. Increasing aspiration temperature was found to enhance product yield with a negligible influence on CNT quality (as determined by Raman spectroscopy G:D ratio values). The growth temperature was found to have a pronounced influence over CNT product yield and quality. The product yield was found to increase from 700 to $900^{\circ} \mathrm{C}$, followed by a slight decrease at $1000^{\circ} \mathrm{C}$. Notably, a $\sim 3$-fold increase in CNT quality was observed from 900 to $1000{ }^{\circ} \mathrm{C}$. This is interesting to note, given that prior work with FeMoC demonstrated poor catalytic performance at growth temperatures below $900{ }^{\circ} \mathrm{C}[16,17,23,24]$. The results herein, and from prior work, suggest that FeMoC has a temperature dependent "activation" mechanism for the catalytic growth of CNTs. The increase in injection rates resulted in a slight increase in product yield from $3.7 \mathrm{mg}$ to $5.4 \mathrm{mg}$ at the expense of CNT quality with Raman G:D ratio values of 4.2 to 1.58 , respectively. The catalyst concentration results demonstrated that concentration either too low or too high will fail to produce CNTs, suggesting that optimized catalyst concentrations are required for $\mathrm{CNT}$ growth. The carbon source experiments reveal that both product yield and CNT quality were improved with increasing addition of toluene (wt.\%) in $\mathrm{EtOH}$, indicating that toluene is a more favorable carbon source under the CCVD conditions employed. 
Supplementary Materials: Supplementary materials can be found at http:/ / www.mdpi.com/2311-5629/4/1/ 17/s1. Figure S1: The Raman spectra $(514.5 \mathrm{~nm})$ for CNT samples grown using FeMoC as a catalyst.

Acknowledgments: Financial support for this work is provided by the Robert A. Welch Foundation (C-0002), the NSF IRISE training program at Rice University (NSF EHR-0966303), and the Welsh Government Sêr Cymru Programme.

Author Contributions: Gibran L. Esquenazi performed all the experiments and UV-vis, Raman spectroscopy, FT-IR, SEM, and TGA characterization. Bruce Brinson performed the TEM characterization. Andrew R. Barron provided guidance to experiments. Both authors contributed to writing the manuscript.

Conflicts of Interest: The authors declare no conflict of interest.

\section{References}

1. De Volder, M.F.; Tawfick, S.H.; Baughman, R.H.; Hart, A.J. Carbon nanotubes: Present and future commercial applications. Science 2013, 339, 535-539. [CrossRef] [PubMed]

2. Ameli, A.; Arjmand, M.; Sundararaj, U. Effects of synthesis catalyst and temperature on broadband dielectric properties of nitrogen-doped carbon nanotube/polyvinylidene fluoride nanocomposites. Carbon 2016, 106, 260-278. [CrossRef]

3. Arjmand, M.; Ameli, A.; Sundararaj, U. Employing nitrogen doping as innovative technique to improve broadband dielectric properties of carbon nanotube/polymer nanocomposites. Macromol. Mater. Eng. 2016, 301, 555-565. [CrossRef]

4. Pawar, S.P.; Arjmand, M.; Gandi, M.; Bose, S.; Sundararaj, U. Critical insights in understanding effects of synthesis temperature and nitrogen doping towards charge storage capability and microwave shielding in nitrogen-doped carbon nanotube/polymer nanocomposites. RSC Adv. 2016, 6, 63224-63234. [CrossRef]

5. McEuen, P.L.; Fuhrer, M.S.; Park, H. Single walled carbon nanotube electronics. IEEE Trans. Nanotechnol. 2002, 1, 78-85. [CrossRef]

6. Liu, X.M.; Huang, Z.D.; Oh, S.W.; Zhang, B.; Ma, P.C.; Yuen, M.M.F.; Kim, J.K. Carbon nanotube (CNT)-based composites as electrode material for rechargeable Li-ion batteries: A review. Compos. Sci. Technol. 2012, 72, 121-144. [CrossRef]

7. Cheung, C.L.; Kurtz, A.; Park, H.; Lieber, C.M. Diameter-controlled synthesis of carbon nanotubes. J. Phys. Chem. B 2002, 106, 2429-2433. [CrossRef]

8. Orbaek, A.W.; Owens, A.C.; Crouse, C.C.; Pint, C.L.; Hauge, R.H.; Barron, A.R. Single walled carbon nanotube growth and chirality dependence on catalyst composition. Nanoscale 2013, 5, 9848-9859. [CrossRef] [PubMed]

9. Nasibulin, A.G.; Pikhitsa, P.V.; Jiang, H.; Kauppinen, E.I. Correlation between catalyst particle and single-walled carbon nanotube diameters. Carbon 2005, 43, 2251-2257. [CrossRef]

10. Schäffel, F.; Rümmeli, M.H.; Kramberger, C.; Queitsch, U.; Mohn, E.; Kaltofen, R.; Pichler, T.; Büchner, B.; Rellinghaus, B.; Schultz, L. Tailoring the diameter, density and number of walls of carbon nanotubes through predefined catalyst particles. Phys. Status Solidi A 2008, 205, 1382-1385. [CrossRef]

11. Fiawoo, M.-F.C.; Bonnot, A.M.; Amara, H.; Bichara, C.; Thibault-Pénisson, J.; Loiseau, A. Evidence of correlation between catalyst particles and the single-wall carbon nanotube diameter: A first step towards chirality control. Phys. Rev. Lett. 2012, 108, 195503. [CrossRef] [PubMed]

12. Wang, X.; Li, Q.; Xie, J.; Jin, Z.; Wang, J.; Li, Y.; Jiang, K.; Fan, S. Fabrication of ultralong and electrically uniform single-walled carbon nanotubes on clean substrates. Nano Lett. 2009, 9, 3137-3141. [CrossRef] [PubMed]

13. Kang, L.; Hu, Y.; Zhong, H.; Si, J.; Zhang, S.; Zhao, Q.; Lin, J.; Li, Q.; Zhang, Z.; Peng, L.; et al. Large-area growth of ultra-high-density single-walled carbon nanotube arrays on sapphire surface. Nano Res. 2015, 8, 3694-3703. [CrossRef]

14. Youn, S.K.; Park, H.G. Morphological evolution of Fe-Mo bimetallic catalysts for diameter and density modulation of vertically aligned carbon nanotubes. J. Phys. Chem. C 2013, 117, 18657-18665. [CrossRef]

15. Harutyunyan, A.R.; Pradhan, B.K.; Kim, U.J.; Chen, G.; Eklund, P.C. CVD synthesis of single wall carbon nanotubes under "soft" conditions. Nano Lett. 2002, 2, 525-530. [CrossRef]

16. An, L.; Owens, J.M.; McNeil, L.E.; Liu, J. Synthesis of nearly uniform single-walled carbon nanotubes using identical metal-containing molecular nanoclusters as catalysts. J. Am. Chem. Soc. 2002, 124, 13688-13689. [CrossRef] [PubMed] 
17. Anderson, R.E.; Colorado, R., Jr.; Crouse, C.; Ogrin, D.; Maruyama, B.; Pender, M.J.; Edwards, C.L.; Whitsitt, E.; Moore, V.C.; Koveal, D.; et al. A study of the formation, purification and application as a SWNT growth catalyst of the nanocluster $\left[\mathrm{H}_{\mathrm{x}} \mathrm{PMo}_{12} \mathrm{O}_{40} \subset \mathrm{H}_{4} \mathrm{Mo}_{72} \mathrm{Fe}_{30}\left(\mathrm{O}_{2} \mathrm{CMe}\right)_{15} \mathrm{O}_{254}\left(\mathrm{H}_{2} \mathrm{O}\right)_{98}\right]$. Dalton Trans. 2006, 3097-3107. [CrossRef] [PubMed]

18. Ding, F.; Rosén, A.; Bolton, K. Molecular dynamics study of the catalyst particle size dependence on carbon nanotube growth. J. Chem. Phys. 2004, 121, 2775-2779. [CrossRef] [PubMed]

19. Cassell, A.M.; Raymakers, J.A.; Kong, J.; Dai, H. Large scale CVD synthesis of single-walled carbon nanotubes. J. Phys. Chem. B 1999, 103, 6484-6492. [CrossRef]

20. Lamouroux, E.; Serp, P.; Kihn, Y.; Kalck, P. Identification of key parameters for the selective growth of single or double wall carbon nanotubes on $\mathrm{FeMo} / \mathrm{Al}_{2} \mathrm{O}_{3}$ CVD catalysts. Appl. Catal. Gen. 2007, 323, 162-173. [CrossRef]

21. Zhang, S.; Tong, L.; Hu, Y.; Kang, L.; Zhang, J. Diameter-specific growth of semiconducting SWNT arrays using uniform $\mathrm{Mo}_{2} \mathrm{C}$ solid catalyst. J. Am. Chem. Soc. 2015, 137, 8904-8907. [CrossRef] [PubMed]

22. Harutyunyan, A.R.; Mora, E.; Tokune, T.; Bolton, K.; Rosén, A.; Jiang, A.; Awasthi, N.; Curtarolo, S. Hidden features of the catalyst nanoparticles favorable for single-walled carbon nanotube growth. Appl. Phys. Lett. 2007, 90, 163120. [CrossRef]

23. Edgar, K.; Spencer, J.L. The synthesis of carbon nanotubes from Müller clusters. Curr. Appl. Phys. 2006, 6, 419-421. [CrossRef]

24. Goss, K.; Kamra, A.; Spudat, C.; Meyer, C.; Kögerler, P.; Schneider, C.M. CVD growth of carbon nanotubes using molecular nanoclusters as catalyst. Phys. Status Solidi B 2009, 246, 2494-2497. [CrossRef]

25. Esquenazi, G.L.; Barron, A.R. Reduction kinetics of the nanocluster $\left[\mathrm{H}_{\mathrm{x}} \mathrm{PMo}_{12} \mathrm{O}_{40} \subset \mathrm{H}_{4} \mathrm{Mo}_{72} \mathrm{Fe}_{30}\left(\mathrm{O}_{2} \mathrm{CMe}\right)_{15}\right.$ $\mathrm{O}_{254}\left(\mathrm{H}_{2} \mathrm{O}\right)_{98-\mathrm{y}}(\mathrm{EtOH})_{\mathrm{y}}$ ]. J. Clust. Sci. 2018, 29, 325-335. [CrossRef]

26. Esquenazi, G.L.; Barron, A.R. Understanding the "activation" of the nanocluster $\left[\mathrm{H}_{\mathrm{x}} \mathrm{PMo}_{12} \mathrm{O}_{40} \subset \mathrm{H}_{4} \mathrm{Mo}_{72} \mathrm{Fe}_{30}\right.$ $\left(\mathrm{O}_{2} \mathrm{CMe}\right)_{15} \mathrm{O}_{254}\left(\mathrm{H}_{2} \mathrm{O}\right)_{98-y}\left(\mathrm{H}_{2} \mathrm{O}\right)_{y}$ ] for low temperature growth of carbon nanotubes. J. Clust. Sci. 2018, in press. [CrossRef]

27. Lee, C.J.; Park, J.; Huh, Y.; Lee, J.Y. Temperature effect on the growth of carbon nanotubes using thermal chemical vapor deposition. Chem. Phys. Lett. 2001, 343, 33-38. [CrossRef]

28. Emmenegger, C.; Bonard, J.-M.; Mauron, P.; Sudan, P.; Lepora, A.; Grobety, B.; Züttel, A.; Schlapbach, L. Synthesis of carbon nanotubes over Fe catalyst on aluminium and suggested growth mechanism. Carbon 2003, 41, 539-547. [CrossRef]

29. Young Lee, T.; Han, J.-H.; Hong Choi, S.; Yoo, J.-B.; Park, C.-Y.; Jung, T.; Yu, S.; Yi, W.K.; Han, I.T.; Kim, J.M. Effects of source gases on the growth of carbon nanotubes. Diam. Relat. Mater. 2003, 12, 851-855. [CrossRef]

30. Orbaek, A.W.; Owens, A.C.; Barron, A.R. Increasing the efficiency of single walled carbon nanotube amplification by $\mathrm{Fe}-\mathrm{Co}$ catalysts through the optimization of $\mathrm{CH}_{4} / \mathrm{H}_{2}$ partial pressures. Nano Lett. 2011, 11, 2871-2874. [CrossRef] [PubMed]

31. Orbaek, A.W.; Aggarwal, N.; Barron, A.R. The development of a 'process map' for the growth of carbon nanomaterials from ferrocene by injection CVD. J. Mater. Chem. A 2013, 1, 14122-14132. [CrossRef]

32. Müller, A.; Das, S.K.; Kögerler, P.; Bögge, H.; Schmidtmann, M.; Trautwein, A.X.; Schünemann, V.; Krickemeyer, E.; Preetz, W. A new type of supramolecular compound: Molybdenum-oxide-based composites consisting of magnetic nanocapsules with encapsulated keggin-ion electron reservoirs cross-linked to a two-dimensional network. Angew. Chem. Int. Ed. 2000, 39, 3413-3417. [CrossRef]

33. Mekala, R.; Supriya, S.; Das, S.K. Fate of a giant $\left\{\mathrm{Mo}_{72} \mathrm{Fe}_{30}\right\}$-type polyoxometalate cluster in an aqueous solution at higher temperature: Understanding related keplerate chemistry, from molecule to material. Inorg. Chem. 2013, 52, 9708-9710. [CrossRef] [PubMed]

34. Yin, P.; Wu, B.; Mamontov, E.; Daemen, L.L.; Cheng, Y.; Li, T.; Seifert, S.; Hong, K.; Bonnesen, P.V.; Keum, J.K.; Ramirez-Cuesta, A.J. X-ray and neutron scattering study of the formation of core-shell-type polyoxometalates. J. Am. Chem. Soc. 2016, 138, 2638-2643. [CrossRef] [PubMed]

35. Camacho-López, M.A.; Escobar-Alarcón, L.; Picquart, M.; Arroyo, R.; Córdoba, G.; Haro-Poniatowski, E. Micro-Raman study of the $m-\mathrm{MoO}_{2}$ to $\alpha-\mathrm{MoO}_{3}$ transformation induced by $\mathrm{cw}$-laser irradiation. Opt. Mater. 2011, 33, 480-484. [CrossRef]

36. Müller, A.; Krickemeyer, E.; Das, S.K.; Kögerler, P.; Sarkar, S.; Bögge, H.; Schmidtmann, M.; Sarkar, S. Linking icosahedral, strong molecular magnets $\{\mathrm{Mo}\}$ to layers-A solid-state reaction at room temperature. Angew. Chem. Int. Ed. 2000, 39, 1612-1614. [CrossRef] 
37. Dresselhaus, M.S.; Dresselhaus, G.; Saito, R.; Jorio, A. Raman spectroscopy of carbon nanotubes. Phys. Rep. 2005, 409, 47-99. [CrossRef]

38. Ferrari, A.C.; Basko, D.M. Raman spectroscopy as a versatile tool for studying the properties of graphene. Nat. Nanotechnol. 2013, 8, 235-246. [CrossRef] [PubMed]

39. Plata, D.L.; Meshot, E.R.; Reddy, C.M.; Hart, A.J.; Gschwend, P.M. Multiple alkynes react with ethylene to enhance carbon nanotube synthesis, suggesting a polymerization-like formation mechanism. ACS Nano 2010, 4, 7185-7192. [CrossRef] [PubMed]

40. Nessim, G.D.; Seita, M.; Plata, D.L.; O’Brien, K.P.; Hart, A.J.; Meshot, E.R.; Reddy, C.M.; Gschwend, P.M.; Thompson, C.V. Precursor gas chemistry determines the crystallinity of carbon nanotubes synthesized at low temperature. Carbon 2011, 49, 804-810. [CrossRef]

41. Bandow, S.; Asaka, S.; Saito, Y.; Rao, A.M.; Grigorian, L.; Richter, E.; Eklund, P.C. Effect of the growth temperature on the diameter distribution and chirality of single-wall carbon nanotubes. Phys. Rev. Lett. 1998, 80, 3779-3782. [CrossRef]

42. Jourdain, V.; Bichara, C. Current understanding of the growth of carbon nanotubes in catalytic chemical vapour deposition. Carbon 2013, 58, 2-39. [CrossRef]

43. Kumar, M.; Ando, Y. Chemical vapor deposition of carbon nanotubes: A review on growth mechanism and mass production. J. Nanosci. Nanotechnol. 2010, 10, 3739-3758. [CrossRef] [PubMed]

44. Peng, F.; Luo, D.; Sun, H.; Wang, J.; Yang, F.; Li, R.; Yang, J.; Li, Y. Diameter-controlled growth of aligned single-walled carbon nanotubes on quartz using molecular nanoclusters as catalyst precursors. Chin. Sci. Bull. 2013, 58, 433-439. [CrossRef]

45. Kuwana, K.; Endo, H.; Saito, K.; Qian, D.; Andrews, R.; Grulke, E.A. Catalyst deactivation in CVD synthesis of carbon nanotubes. Carbon 2005, 43, 253-260. [CrossRef]

46. Orbaek, A.W.; Barron, A.R. Towards a 'catalyst activity map' regarding the nucleation and growth of single walled carbon nanotubes. J. Exp. Nanosci. 2015, 10, 66-76. [CrossRef]

47. Obrey, S.J.; Bott, S.G.; Barron, A.R. A Lewis base promoted alkyl/alkoxide ligand redistribution: Reaction of $\left[\mathrm{Me}_{2} \mathrm{Al}\left(\mu-\mathrm{OCPh}_{3}\right)\right]_{2}$ with THF. Organometallics 2001, 20, 5119-5124. [CrossRef]

48. Gomez-Ballesteros, J.L.; Burgos, J.C.; Lin, P.A.; Sharma, R.; Balbuena, P.B. Nanocatalyst shape and composition during nucleation of single-walled carbon nanotubes. RSC Adv. 2015, 5, 106377-106386. [CrossRef] [PubMed]

49. Brouwer, L.D.; Mueller-Markgraf, W.; Troe, J. Thermal decomposition of toluene: A comparison of thermal and laser-photochemical activation experiments. J. Phys. Chem. 1988, 92, 4905-4914. [CrossRef]

50. Eng, R.A.; Gebert, A.; Goos, E.; Hippler, H.; Kachiani, C. Incubation times, fall-off and branching ratios in the thermal decomposition of toluene: Experiments and theory. Phys. Chem. Chem. Phys. 2002, 4, 3989-3996. [CrossRef]

51. Li, J.; Kazakov, A.; Dryer, F.L. Experimental and numerical studies of ethanol decomposition reactions. J. Phys. Chem. A 2004, 108, 7671-7680. [CrossRef]

52. Park, J.; Zhu, R.S.; Lin, M.C. Thermal decomposition of ethanol. I. ab Initio molecular orbital/ Rice-Ramsperger-Kassel-Marcus prediction of rate constant and product branching ratios. J. Chem. Phys. 2002, 117, 3224-3231. [CrossRef]

53. Gómez-Gualdrón, D.A.; Beetge, J.M.; Burgos, J.C.; Balbuena, P.B. Effects of precursor type on the CVD growth of single-walled carbon nanotubes. J. Phys. Chem. C 2013, 117, 10397-10409. [CrossRef]

54. Zhang, G.; Mann, D.; Zhang, L.; Javey, A.; Li, Y.; Yenilmez, E.; Wang, Q.; McVittie, J.P.; Nishi, Y.; Gibbons, J.; et al. Ultra-high-yield growth of vertical single-walled carbon nanotubes: Hidden roles of hydrogen and oxygen. Proc. Natl. Acad. Sci. USA 2005, 102, 16141-16145. [CrossRef] [PubMed]

55. Li, J.; Ke, C.T.; Liu, K.; Li, P.; Liang, S.; Finkelstein, G.; Wang, F.; Liu, J. Importance of diameter control on selective synthesis of semiconducting single-walled carbon nanotubes. ACS Nano 2014, 8, 8564-8572. [CrossRef] [PubMed]

56. Moon, C.Y.; Kim, Y.S.; Lee, E.C.; Jin, Y.G.; Chang, K.J. Mechanism for oxidative etching in carbon nanotubes. Phys. Rev. B 2002, 65, 155401. [CrossRef]

(C) 2018 by the authors. Licensee MDPI, Basel, Switzerland. This article is an open access article distributed under the terms and conditions of the Creative Commons Attribution (CC BY) license (http:/ / creativecommons.org/licenses/by/4.0/). 